\title{
Deaths from Acute Lead Poisoning
}

\author{
F. W. ALEXANDER and H. T. DELVES \\ From the Department of Chemical Pathology, The Hospital for Sick Children, and Institute of Child Health, London
}

\begin{abstract}
Alexander, F. W., and Delves, H. T. (1972). Archives of Disease in Childhood, 47, 446. Deaths from acute lead poisoning. The three fatal cases of acute lead poisoning described show the difficulty experienced in reaching an early diagnosis of lead intoxication. A rapid micromethod is now available for the determination of whole blood lead levels on small samples of blood, using atomic absorption spectrophotometry.

Given an increased awareness of acute lead intoxication, the rapid confirmation of the diagnosis by the micromethod, and the early institution of adequate chelation therapy, then fatalities such as those described should not occur in the future.
\end{abstract}

Lead poisoning in children is diagnosed less frequently in this country than it is in North America. The available figures suggest an incidence in this country of less than 1 per 10,000 children at risk, whereas in certain parts of the United States (notably Chicago) it is greater than $1 \%$ of these children (Barltrop, 1971). This may be explained either by a lower absolute incidence of lead poisoning in this country or by a certain lack of awareness of British paediatricians for the likelihood of lead intoxication.

The children at greatest risk are those between the ages of 1 and 5 years, living in old dilapidated houses (McLaughlin, 1956; Chisholm and Harrison, 1956); there is frequently an associated history of pica, particularly for old paint and plaster (American Academy of Pediatrics, 1969).

The diagnosis may be easily overlooked because of the absence of any specific symptoms or signs, and made more difficult because, until recently, there was no specific diagnostic test available which was both rapid and reliable. The urinary coproporphyrin test requires a freshly voided specimen of urine. This may be difficult to obtain from a child who has been vomiting for a number of days, and false negative results can be obtained in the face of heavy intoxication (American Academy of Pediatrics, 1969). The most reliable index of lead intoxication is a blood-lead analysis. However, whole blood lead determinations by the dithizone method required between 2 and $10 \mathrm{ml}$ blood, and a minimum of 8 hours was needed for the analysis. The determination of lead in blood

Received 1 November 1971. by direct solvent extraction after protein precipitation has been reported (Selander and Cramér, 1968). Though the analysis time was reduced to 90 minutes, $5 \mathrm{ml}$ blood were needed for a single determination.

However, a recently developed microatomic absorption method is capable of providing an accurate blood-lead analysis with only $10 \mu \mathrm{l}$ of blood, in less than 5 minutes (Delves, 1970). This is of value as a diagnostic test for lead poisoning in children who are seriously ill and for whom delay could result in brain damage or death.

We report 3 cases of children dying from acute lead encephalopathy in hospitals around London, within one month of each other, whose blood was sent to this laboratory for blood lead analysis by the rapid micromethod mentioned above.

\section{Case Reports}

Case 1. Aged 4 years 9 months, a Pakistani girl, was admitted 19 May 1970 because her general practitioner noticed that she was very pale and unwell. She had been vomiting for 2 days before admission. A full history was not obtainable because of language difficulties. On examination, she was anaemic and had a harsh systolic murmur audible over the whole praecordium. She was fully conscious, alert, and had no demonstrable neurological defect. Investigations revealed an $\mathrm{Hb}$ of $6 \mathrm{~g} / 100 \mathrm{ml}$. The urine contained protein and $1 \%$ glycosuria. The serum iron was 10 $\mu \mathrm{g} / 100 \mathrm{ml}$ blood; blood sugar $91 \mathrm{mg} / 100 \mathrm{ml} ; x$-ray of chest and heart normal. An $x$-ray of the long bones was compatible with moderately severe rickets. She received general supportive treatment for a few days but suddenly became comatose 6 days after admission. At that time a definite history of pica and paint ingestion 
was obtained. The whole blood lead was $111 \mu \mathrm{g} / 100$ ml. Treatment was started with parenteral ethylenediamine-tetra-acetic acid (EDTA) but she died 4 days later. Necropsy showed gross oedema of the brain and a blood lead level of $92 \mu \mathrm{g} / 100 \mathrm{ml}$. On examination of the contents of the small bowel, a large number of very small paint flakes were found some of them 6 layers thick and containing 10 p.p.m. of lead. However, the family used 'surma' for facial decoration which contained more than $10 \%$ of lead by weight, and this is therefore implicated as the cause of poisoning as has been reported previously (Warley, Blackledge, and O’Gorman, 1968).

Case 2. Aged 2 years 8 months, a boy of English parentage was admitted on 19 July 1970 with one year's history of pica, particularly for paint scrapings from the wall. He was unwell for 1 week before admission and had vomited the day before. Flecks of paint were noticed in his stools.

On examination he was fully conscious and alert but experienced frequent attacks of abdominal colic. Within 6 hours of admission he became deeply unconscious followed by a brief but severe generalized convulsion.

Investigations at this time, 8 hours after admission, revealed a whole blood lead of $350 \mu \mathrm{g} / 100 \mathrm{ml}$; scattered granular opacities were seen on $x$-ray of the abdomen. There were no porphyrins detected in the urine.

Two hours after becoming comatose he required artificial ventilation. His stomach and colon were washed out. He was given dexamethasone $2 \mathrm{mg} \mathrm{6-}$ hourly and $20 \%$ mannitol i.v. EDTA alone was also started. He died 2 days later.

Case 3. A 3-year-old West Indian girl was admitted on 19 July 1970 to a third hospital with a 2-week history of anorexia and vomiting.

On examination she was fully conscious and alert but with some slight oedema of the eyelids. The urine was faintly positive to Clinitest. The following morning she had a left-sided convulsion and became comatose. Her fundi showed blurring of both disc margins. Spontaneous respirations ceased and she was therefore ventilated artificially and transferred to a neurosurgical unit where bilateral burr holes were performed which showed only that the brain was very oedematous.

Investigations at this time, some 24 hours after admission revealed a whole blood lead of $260 \mu \mathrm{g} / 100 \mathrm{ml}$ and grossly raised urinary coproporphyrin excretion.

Treatment was started with a combination of 2,3 di-mercapto-l-propanol (BAL-50 mg 4-hourly i.v.) and EDTA (150 mg, 4-hourly) 4 hours after an initial dose of BAL.

She was also given i.v. mannitol but died 36 hours after the first convulsion.

Her two small sibs were found to have blood leads of $52 \mu \mathrm{g} / 100 \mathrm{ml}$ and $57 \mu \mathrm{g} / 100 \mathrm{ml}$ and the parents finally admitted that their daughter might have been eating dirt and paint in the garden. Samples taken from an old door in the garden revealed a lead content of $12 \%$ $\mathrm{Pb}$ by weight.

\section{Discussion}

These three cases showed a number of disturbing features of lead poisoning which have been previously reported (American Academy of Pediatrics, 1969; Chisholm, 1968). All three children were fully conscious and alert on admission and then rapidly became comatose, two within a few hours, the third a few days later. All three had an associated history of pica, lived in old houses, and developed anorexia and vomiting before admission. Two children had glycosuria; in the urine of one (Case 3) the coproporphyrins were grossly raised, but in another (Case 2) they were not detected. This illustrated the unreliability of testing for coproporphyrinuria in the diagnosis of lead poisoning. No data were available for the third child, Case 1. Once lead poisoning had been suspected the diagnosis was quickly established by the determination of whole blood lead levels by the rapid micromethod. However, the delay in reaching this tentative diagnosis which amounted, respectively to 6 days, 8 hours, and over 24 hours, together with the incompleteness of treatment of the first two children, and the complication of surgery before effective treatment of the third child, resulted in the death of all three.

The management of acute lead poisoning has been recently reviewed by Chisholm (1968). In his study of 52 children he found that though treatment with EDTA alone had reduced mortality to $25 \%$, there was a worsening in the child's condition for the first 24 to 48 hours with an increase in the CSF pressure. When a combination of BAL and EDTA was used, no deterioration occurred, blood levels were reduced more quickly and the urinary excretion of lead was greater. He therefore recommends an initial injection of BAL (3-5 mg/ $\mathrm{kg}$ ) followed after 4 hours by a combination of BAL (above dose) and EDTA ( $8 \mathrm{mg} / \mathrm{kg}$ ) given parenterally at 4-hourly intervals for 5 days.

Neurosurgery and gastrointestinal lavage should be avoided. Oral feeds should be withheld and homoeostasis maintained parenterally. Mannitol may be used sparingly but steroids are probably of questionable value. Any convulsions should be carefully suppressed with appropriate anticonvulsants.

The most critical factor affecting the success of the treatment appears to be the time interval between the poisoning and the starting of treatment. In Chisholm's series of 24 cases of lead encephalopathy treated as outlined above, there were no fatalities. Consequently, to avoid further fatalities 
from acute lead intoxication in this country, clinicians must be more aware of the likelihood of lead poisoning, should confirm the diagnosis with a blood-lead analysis which can now be determined rapidly on a small sample of heparinized whole blood, and start treatment as soon as possible using a regimen such as outlined by Chisholm (1968).

We should like to thank the consultants at the three referring hospitals for their permission to publish the clinical details, and Professor Barbara E. Clayton for her help in preparing the paper.

\section{REFERENCES}

American Academy of Pediatrics, Subcommittee on Accidental Poisoning (1969). Prevention, diagnosis, and treatment of lead poisoning in childhood. Pediatrics, 44, 291.
Barltrop, D. (1971). Lead poisoning. Archives of Disease in Childhood, 46, 233.

Chisholm, J. J., Jr. (1968). The use of chelating agents in the treatment of acute and chronic lead intoxication in childhood. Fournal of Pediatrics, 73, 1.

Chisholm, J. J., Jr., and Harrison, H. E. (1956). The exposure of children to lead. Pediatrics, 18, 943.

Delves, H. T. (1970). A micro-sampling method for the rapid determination of lead in blood by atomic-absorption spectrophotometry. Analyst, 95, 431.

McLaughlin, M. C. (1956). Lead poisoning in children in New York City, 1950-1954; an epidemiologic study. New York State fournal of Medicine, 56,3711 .

Selander, S. and Cramér, K., (1968). Determination of lead in blood by atomic absorption spectrophotometry. British fournal of Industrial Medicine, 25, 209.

Warley, M. A., Blackledge, P., and O'Gorman, P. (1968), Lead poisoning from eye cosmetic. British Medical fournal, 1, 17.

Correspondence to Dr. F. W. Alexander, Heavy Metals Unit, Institute of Child Health, 30 Guilford Street, London WC1N 1EH. 